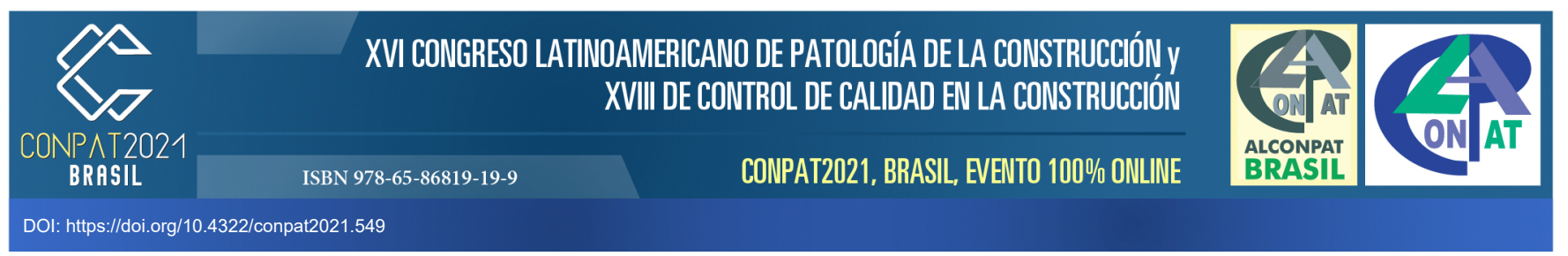

\title{
ANÁLISE DO GRAU DE DETERIORAÇÃO DA ESTRUTURA DE PASSARELAS EM MANAUS, BRASIL.
}

\author{
T. C. CAVALVANTE ${ }^{1 *}$, V. S. ARAÚJO ${ }^{2}$ \\ *Autor de Contacto: tiagocanavarro.eng@gmail.com \\ ${ }^{1}$ Coordenação de Engenharia Civil, Escola Superior de Tecnologia, Universidade do Estado do Amazonas, Manaus, \\ Brasil. \\ ${ }^{2}$ Coordenação de Engenharia Civil, Escola Superior de Tecnologia, Universidade do Estado do Amazonas, Manaus, \\ Brasil.
}

\section{RESUMO}

Objetivou-se mensurar o dano de passarelas em concreto armado, como desplacamentos, eflorescência, fissuras, e fenômenos corrosivos, pelo método do Grau de Deterioração da Estrutura (GDE/UnB) em 5 passarelas em Manaus, Brasil. Através de inspeções visuais, calculou-se o GDE de cada passarela após identificação das manifestações patológicas em seus elementos, grau dos danos, e a importância de cada elemento estrutural analisado. O GDE calculado é classificado em "baixo" (GDE < 15) até "crítico" (GDE > 100) com respectivas ações prescritivas. Os GDEs calculados foram respectivamente: P01: 46,91; P02: 127,96; P03: 15,17; P04: 47,99; P05:17,22. O método revelou-se eficaz na mensuração do dano das estruturas e indicou precisamente os elementos em maior necessidade de reparos, facilitando o planejamento de ações de manutenção.

Palavras clave: Passarelas, Inspeção, Classificação de estruturas, Patologias.

\begin{abstract}
The aim of this paper was to measure damange on reinforced concrete pedestrian bridges, such as efflorescence, cracking, corrosion phenomena, through the Structure Deterioration Degree (GDE/University of Brasília - UnB) on 5 pedestrian bridges in Manaus, Brazil. Visual Inspections were carried out in order to calculate the respective degrees of deterioration, after identifying damages and defects on its elements, their scale and the structural significance of the analyzed. The Deterioration Degrees are classified as "low" (under 15) until "critical" (over 100) with respective recommended remediations. The Degrees calculated were respectively: P01: 46,91; P02: 127,96; P03: 15,17; P04: 47,99; P05:17,22. The method revealed itself as effective on structural damage evaluation and precisely pointed the elements on bigger urgency for repairs, easening maintencance procedures planning.
\end{abstract}

Palavras clave: Pedestrian Bridges, Inspections, Strucutures evaluation, Pathology.

\section{INTRODUÇÃO}


As passarelas brasileiras tem apresentado estado de conservação frequentemente precário, indicando negligência governamental quanto às vistorias preventivas e manutenções, cenário enfrentado também por pontes e viadutos. Vitório (2006) já havia ressaltado esta ausência de ações públicas para a conservação e manutenção de pontes e viadutos, representando grande risco à sociedade. Em Manaus, Brasil, esta negligência pode ser evidenciada com o recente colapso parcial de uma passarela, em 2019, ilustrada na Figura 1. Ademais, acidentes como impactos de veículos leves e pesados na estrutura destas passarelas, têm sido amplamente noticiados, estes podendo agravar as condições de estabilidade destas estruturas.

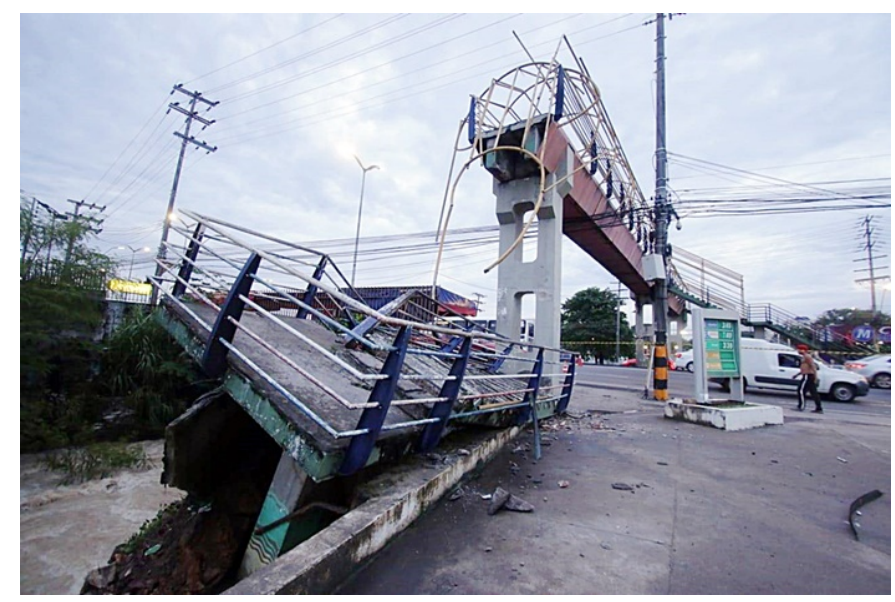

O estado de preservação de muitas passarelas, especialmente em concreto armado, revela-se precário ao olhar leigo, como na Figura 2. Esta problemática engloba a discussão da durabilidade das estruturas de concreto armado. De natureza alcalina e relativamente permeável, as estruturas de concreto armado se tornam vulneráveis à diversos processos físicos e químicos de degradação, como a penetração da água, que muitas vezes possui acidez elevada ou carrega íons e substâncias prejudiciais ao concreto e ao aço (MEHTA e MONTEIRO, 2014).

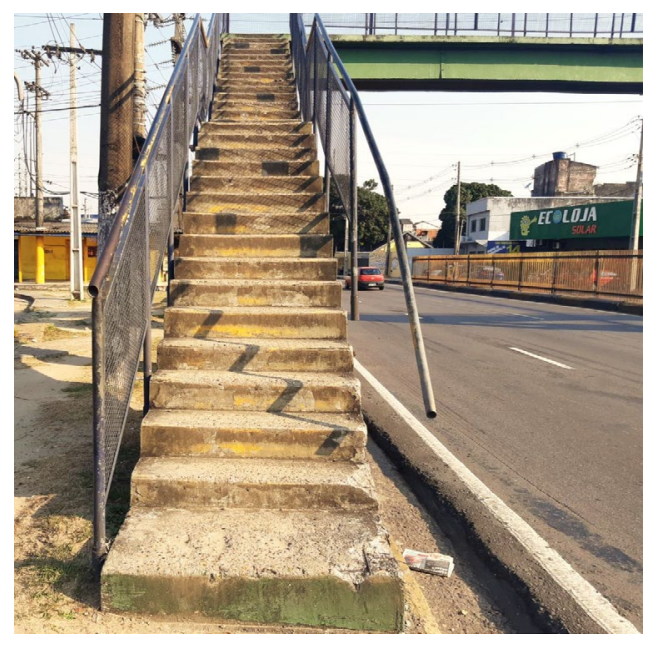

\subsection{Inspeções em Obras de Arte Especiais}


No Brasil, pontes, viadutos, passarelas e viadutos são referenciados como Obras de Arte Especiais (OAEs) - análogo ao termo francês Ouvrage d'art. Quanto aos procedimentos de inspeção de obras de arte especiais em concreto, o Brasil dispõe de referencial normativo, a Norma Brasileira (NBR) 9452:2019, que dispõe dos requisitos para inspeções de OAEs em concreto, e caracteriza os tipos de inspeção, assim como dispõe das premissas para elaboração de relatório e classificação das OAEs em uma pontuação específica, referente a parâmetros de durabilidade, funcionalidade e parâmetros estruturais. A partir deste procedimento, pode-se classificar uma estrutura de 5 níveis de acordo com os parâmetros citados.

Neste trabalho, optou-se, porém, a metodologia que tem sido desenvolvida na Universidade Nacional de Brasília desde Castro (1994), chamada do Grau de Deterioração da Estrutura. Sua última adaptação fora feita por Verly (2015), a partir da versão implementada por Euqueres (2011), que realizou estudo para auxiliar na análise de OAE's. Esta metodologia resulta no cálculo de um grau de deterioração, variando de 0 a 282,8 , considerando pontuações ponderadas para cada anomalia observada nos elementos analisados. Os danos calculados acima de 100, são classificados como críticos.

A metodologia utilizada foi preferida à norma brasileira, apesar de mais atual, em vista do rigor matemático para o cálculo do grau de deterioração, que realiza a avaliação da OAE a partir de todos os elementos isoladamente, não da estrutura como um todo, abordagem esta da norma brasileira. Verly (2015) ressalta que estes fatores contribuem para a diminuição da subjetividade da inspeção e possibilita a elencagem de OAEs, quando considerando um sistema de gestão de obras de arte especiais.

\section{MATERIAIS E MÉTODOS}

Neste trabalho utilizou-se a Metodologia GDE/UnB adaptada por Verly (2015) para a avaliação de Obras de Arte Especiais. Para o cálculo do grau de deterioração da estrutura, são definidos os graus de dano para cada elemento da estrutura, e em seguida, calcula-se os graus de deterioração dos elementos e das famílias.

\subsection{Fator de relevância estrutural (Fr)}

Os elementos da estrutura devem ser agrupados de acordo com as suas características estruturais e sua função estrutural no conjunto. É possível que elementos de iguais denominações (como vigas) possuam um fator de relevância distintos por desempenharem papeis diferentes na estabilidade da estrutura. Os fatores de relevância estrutural para cada família de elementos em OAEs estão descritos na Tabela 1 .

Tabela 1: Fatores de relevância estrutural das famílias de elementos (Fr). Fonte: Verly (2015).

\begin{tabular}{lc}
\multicolumn{1}{c}{ Família } & Fr \\
\hline Barreiras, guarda-corpo, guarda rodas, pista de rolamento & 1 \\
Juntas de dilatação & 2 \\
Transversinas, cortinas, alas & 3 \\
Lajes, fundações, vigas secundárias, aparelhos de apoio & 4 \\
Vigas e pilares principais & 5 \\
\hline
\end{tabular}

\subsection{Fator de ponderação do dano (Fp)}


Fator que visa quantificar a importância relativa de um determinado dano, variando de 1 a 5 . Os critérios relacionam-se com às condições gerais de estética, funcionalidade e segurança dos elementos de uma família, tendo em vista as manifestações patológicas passíveis de verificação.

\subsection{Fator de intensidade do dano (Fi)}

Fator que classifica a gravidade e evolução de uma manifestação de dano em um determinado elemento, segundo uma escala de 0 a 4, descrito na Tabela 2. A Tabela 3 exemplifica fatores de intensidade do dano para duas manifestações patológicas específicas. Uma vez defínidos os fatores de ponderação e intensidade, é possivel então calcular o grau do dano de um elemento.

Tabela 2: Fatores de intensidade do dano.

\begin{tabular}{lc}
\hline \multicolumn{1}{c}{ Descrição } & $\mathbf{F}_{\mathbf{i}}$ \\
\hline Elementos sem lesões & 0 \\
Elementos com lesões leves & 1 \\
Elementos com lesões toleráveis & 2 \\
Elementos com lesões graves & 3 \\
Elementos em estado crítico & 4 \\
\hline
\end{tabular}

Tabela 3: Exemplos de fatores de intensidade do dano para manchas e falhas de concretagem

\begin{tabular}{|c|c|c|}
\hline Dano & $\mathbf{F}_{\mathbf{i}}$ & Descrição \\
\hline \multirow{4}{*}{ MANCHAS } & 0 & Sem lesões \\
\hline & 2 & $\begin{array}{l}\text { Manchas escuras de pouca extensão, porém significativas }(<50 \% \\
\text { da área visível do elemento estrutural) }\end{array}$ \\
\hline & 3 & Manchas escuras de grande extensão $(>50 \%)$ \\
\hline & 4 & Manchas escuras em todo elemento estrutural (100\%) \\
\hline \multirow{4}{*}{$\begin{array}{c}\text { FALHAS DE } \\
\text { CONCRETAGEM }\end{array}$} & 0 & Sem lesões \\
\hline & 2 & $\begin{array}{l}\text { Manchas escuras de pouca extensão, porém significativas }(<50 \% \\
\text { da área visível do elemento estrutural) }\end{array}$ \\
\hline & 3 & Manchas escuras de grande extensão $(>50 \%)$ \\
\hline & 4 & Manchas escuras em todo elemento estrutural (100\%) \\
\hline
\end{tabular}

\subsection{Grau do Dano (D)}

O grau do dano define em um elemento, os efeitos de cada manifestação observada. Este valor é obtido através do cálculo que relaciona a importância do dano utilizando o fator de ponderação (Fp) e o estado deste dano respectivo através do fator de intensidade (Fi), conforme as expressões 1 e 2 a seguir:

$$
\begin{array}{ll}
D=0,8 * F_{i} F_{p} & \text { Para } \mathrm{F}_{\mathrm{i}} \leq 2,0 \\
D=\left(12 F_{i}-28\right) F_{p} & \text { Para } \mathrm{F}_{\mathrm{i}} \geq 3,0
\end{array}
$$




\subsection{Grau de deterioração de um elemento (Gde)}

A partir do cálculo da identificação e cálculo do grau do dano de todas as manifestações, é possível calcular o seu grau de deterioração. Este cálculo, expresso na equação 3, faz com que os efeitos do maior dano sejam adicionados aos demais.

$$
G_{d e}=D_{\text {máx }}\left[1+\frac{\sum_{i=1}^{n} D_{i}-D_{\text {máx }}}{\left(\sum_{i=1}^{n} D_{i}\right)}\right]
$$

\subsection{Grau de deterioração de uma família de elementos (Gdf)}

O grau de deterioração de uma família de elementos é obtido através da equação 4. Na metodologia adaptada por Verly, todos os valores de Gde são considerados.

$$
G_{d f}=G_{d e, \operatorname{máx}}\left[1+\frac{\sum_{i=1}^{n} G_{d e, i}-G_{d e, \text { máx }}}{\left(\sum_{i=1}^{n} G_{d e, i}\right)}\right]
$$

\subsection{Grau de deterioração da estrutura (Gd)}

O grau de deterioração da estrutura leva em conta a contribuição de cada família a partir de um grau de deterioração da família majorado $(\mathrm{K})$, descrito na equação 5 . Os valores de $\mathrm{K}$ são obtidos pelo produto de cada Gdf com o seu respectivo fator de relevância estrutural (Fr), disponível na Tabela 1. O grau de deterioração da estrutura Gd é obtido através da equação 6 , também aplicável para Gde e Gdf:

$$
\begin{aligned}
& K_{i}=G_{d f i} * F_{r i} \\
& G_{d}=\frac{K_{\text {máx }}}{7,07}\left[1+\frac{\sum_{i=1}^{n} K_{i}-K_{\text {máx }}}{\left(\sum_{i=1}^{n} K_{i}\right)}\right]
\end{aligned}
$$

\section{RESULTADOS E DISCUSSÕES}

\subsection{Local de Análise}

As passarelas analisadas localizam-se em vias de grande fluxo de veículos e pedestres na cidade de Manaus, Brasil. A localização das passarelas está indicada em mapa na Figura 3:

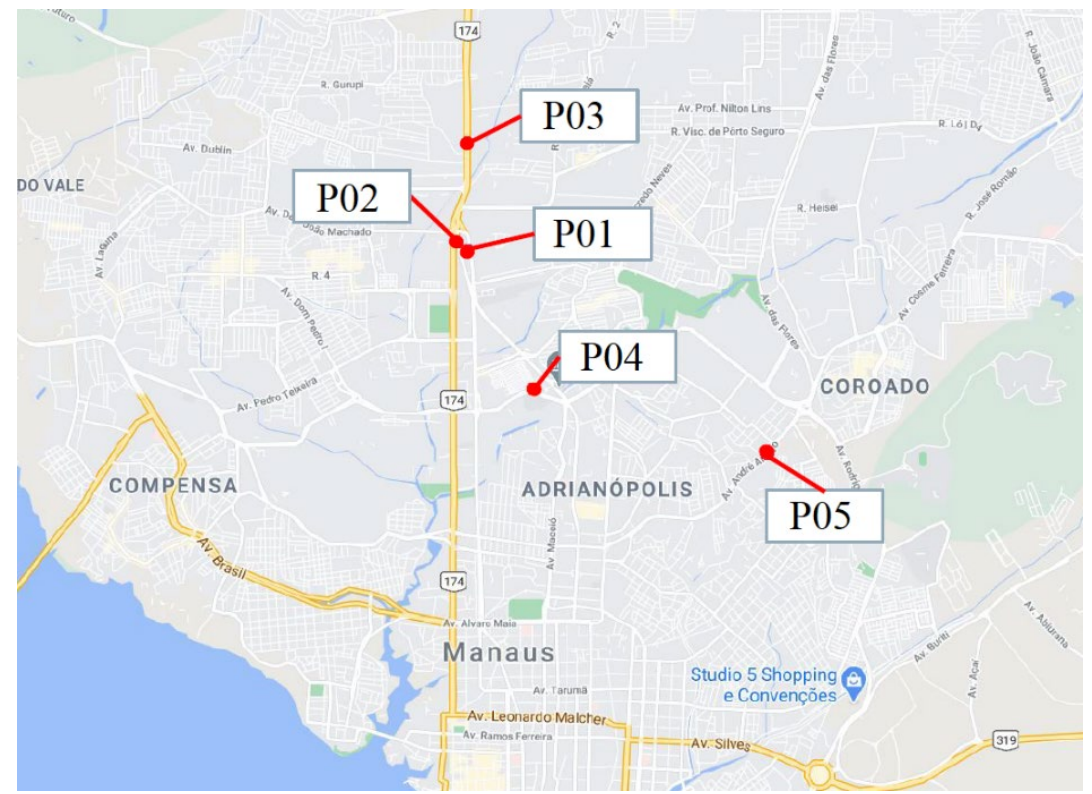

Figura 3: Localização das passarelas analisadas, em Manaus, Brasil. Fonte: Google Maps (2021) 


\subsection{P01}

A passarela 1 apresentou evidente falta de manutenção. Informações quanto à inauguração e identificação não foram encontradas. Nas Figuras 4 e 5 apresentam os danos de maior incidência nesta OAE, as manchas e desplacamentos. A superfície superior das lajes apresentou alguns pontos de desplacamento de trechos superficiais e fissuração. As vigas apresentaram manchas nas faces laterais de escadas e nas faces internas das longarinas. Os pilares apresentaram danos mais graves, com desplacamentos oriundos de fenômenos expansivos e exposição de armaduras, ilustrados nas Figuras 6 e 7. Em um dos pilares foi identificado o crescimento de vegetação (Figura 8).

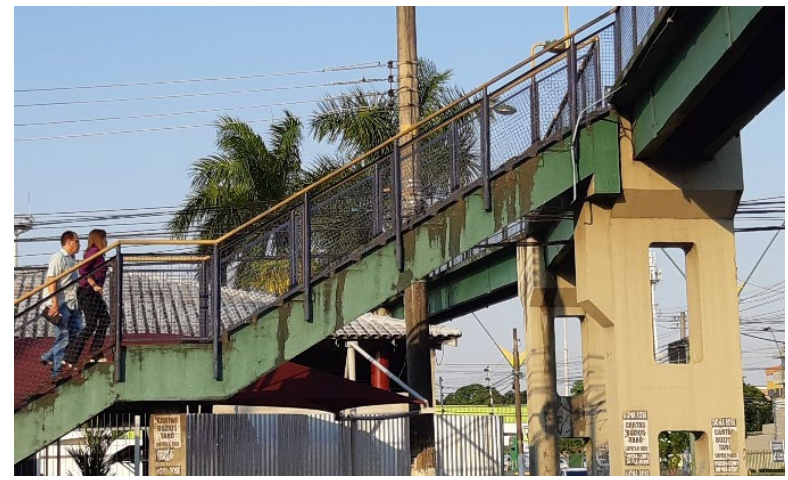

Figura 4: Manchas nas vigas $(\mathrm{Fi}=2)$.

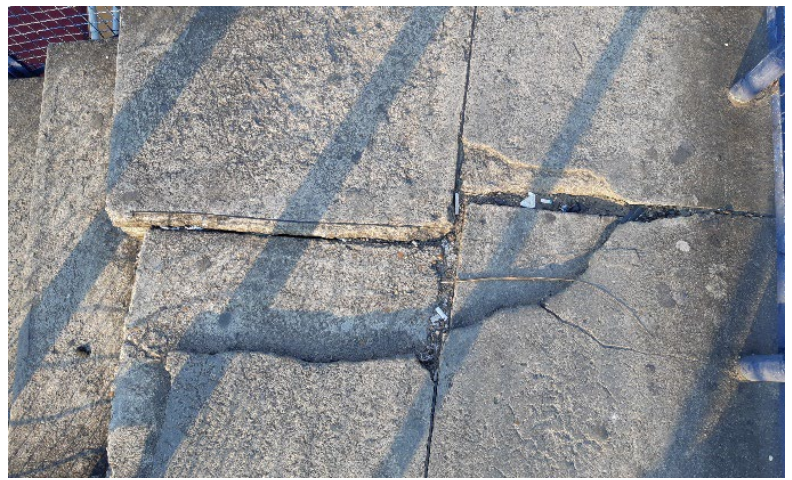

Figura 5: Desplacamento. $(\mathrm{Fi}=2)$.

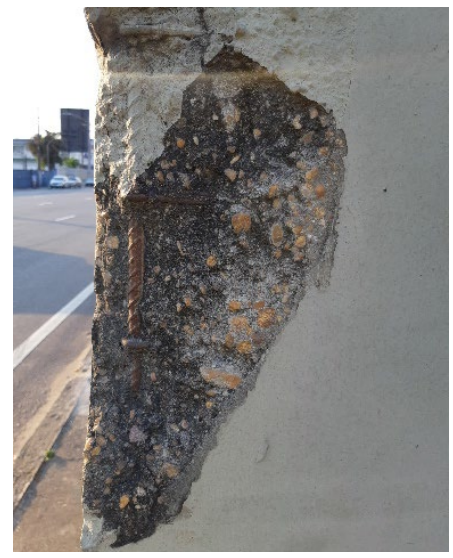

Figura 6: Desplacamento. $(\mathrm{Fi}=3) . \mathrm{P} 01$.

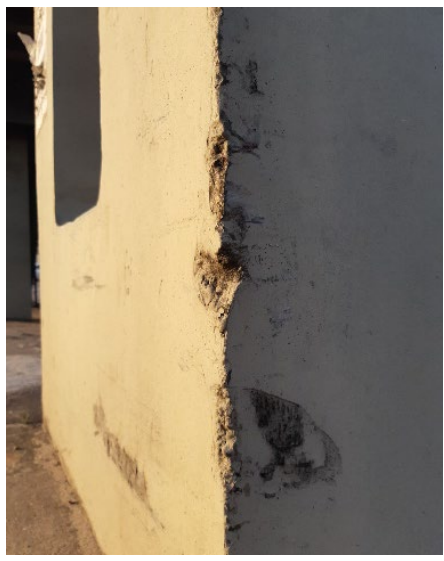

Figura 7: Desplacamento.

$(\mathrm{Fi}=2)$.

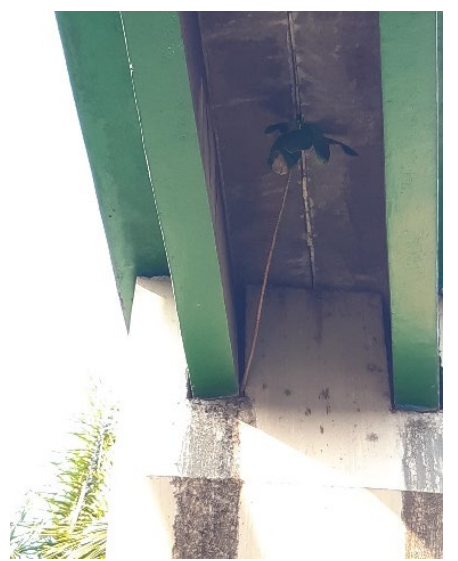

Figura 8: Manchas e vegetação parasitária $(\mathrm{Fi}=3)$.

O grau de deterioração da estrutura calculado resultou em 47,28 ("Médio"). A família dos pilares, apresentou o maior grau de deterioração: 53,12 (“Alto"). Resultados seguem na Tabela 4.

Tabela 4: Grau de deterioração da estrutura. P01.

\begin{tabular}{c|c|c|c|c|c}
\hline Família & $\begin{array}{c}\text { Elemento com } \\
\text { maior dano }\end{array}$ & Gde & Gdf & Fr & Ki \\
\hline Pilares & Pilar 3 & 32,35 & 53,12 & 5,00 & 265,62 \\
\hline Vigas & Viga 29 & 4,80 & 4,70 & 4,00 & 18,82 \\
\hline Lajes & Laje 1 & 7,54 & 14,44 & 4,00 & 57,76 \\
\hline Juntas & - & - & 8,00 & 2,00 & 16,00 \\
\hline Gd & \multicolumn{4}{c}{47,28} \\
\hline
\end{tabular}




\subsection{P02}

A passarela serve de acesso à estação rodoviária de Manaus. Manchas de eflorescência, fissuração, manchas e sujidade apresentaram-se extensivamente, como nas Figuras 9 e 10:

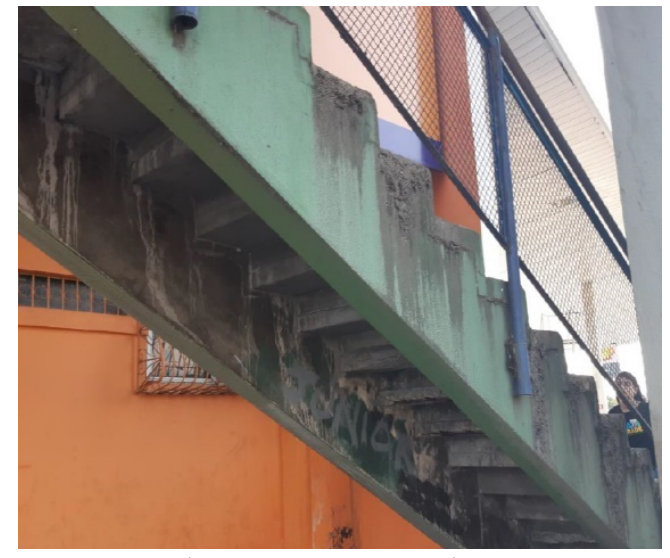

Figura 9: Passarela 2.

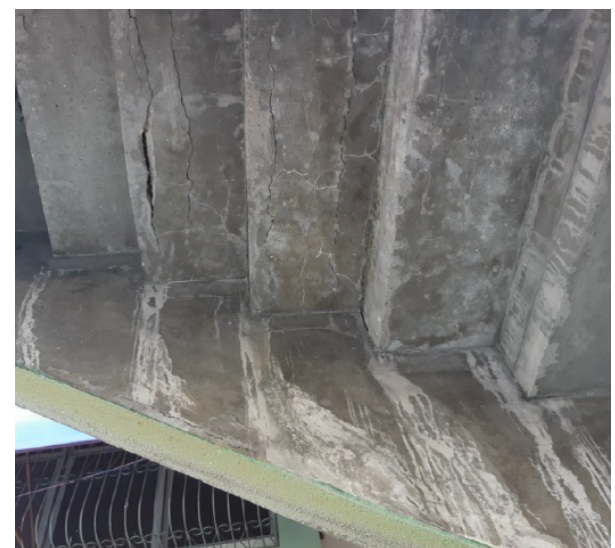

Figura 10: Eflorescência $(\mathrm{Fi}=3)$. Fissuras e indícios de expansão $(\mathrm{Fi}=2)$

A passarela apresentou danos extensivos em todos os elementos, sobretudo nas faces inferiores das lajes das escadas e faces laterais internas de vigas. Este grupo apresentou trechos compreensíveis de desplacamento, fissuração por flexão, manchas, assim como indícios de eflorescência.

A família de lajes também se encontra em estado sofrível segundo a classificação da metodologia, necessitando intervenção de curto prazo. Notavelmente as lajes tiveram o grau de deterioração da família superior ao da estrutura $(\mathrm{Gdf}=148,70)$. Na Figura 11 observa-se pontos de desplacamento, fissuração e corrosão de armaduras. Manchas, como ilustrado na Figura 12, são recorrentes e pode observou-se desagregação de porções de concreto, como no elemento Figura 13.

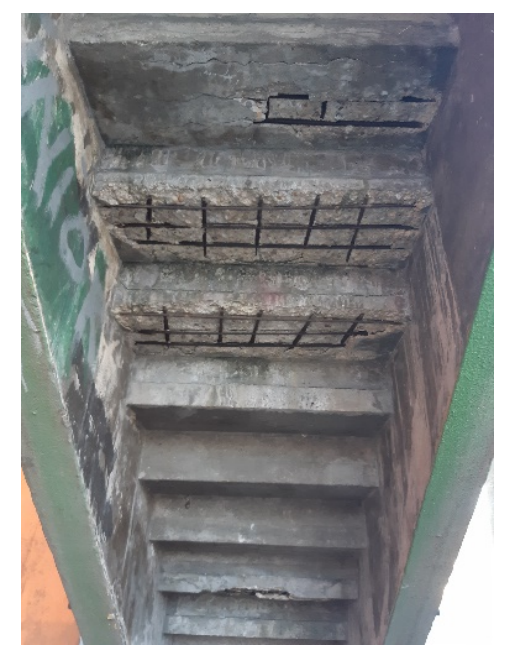

Figura 2: Desplacamento $(\mathrm{Fi}=$

3). Corrosão $(\mathrm{Fi}=2)$.

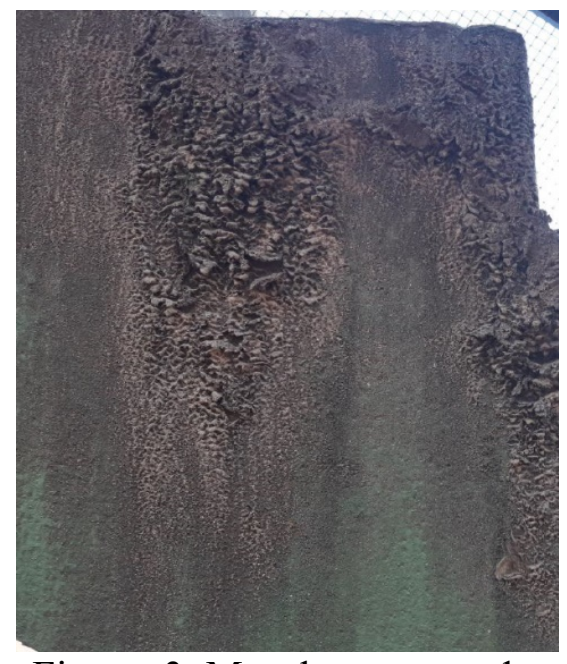

Figura 3: Manchas em estado avançado $(\mathrm{Fi}=2)$.

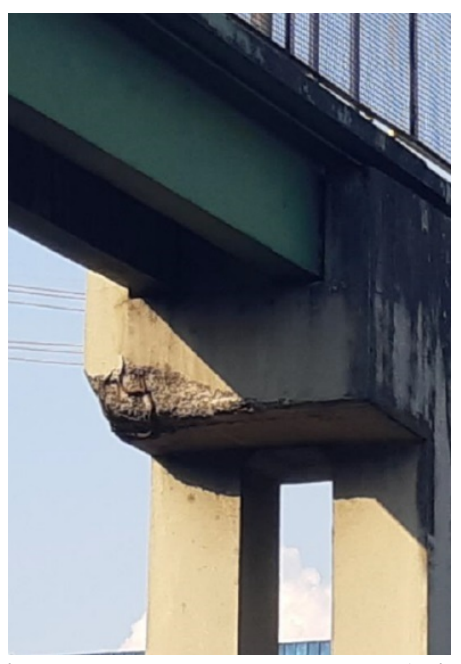

Figura 4: Desagregação $(\mathrm{Fi}=$ 3). Manchas e sujidade $(\mathrm{Fi}=2)$.

Os valores obtidos de grau de deterioração da P02 estão dispostos na Tabela 5. O grau de deterioração da estrutura (Gd) foi de 127,96, considerado "Sofrível”. 
Tabela 5: Grau de deterioração da estrutura. P02.

\begin{tabular}{c|c|c|c|c|c}
\hline Família & $\begin{array}{c}\text { Elemento com } \\
\text { maior dano }\end{array}$ & Gde & Gdf & Fr & Ki \\
\hline Pilares & Pilar 2 & 36,00 & 53,26 & 5,00 & 266,31 \\
\hline Vigas & Viga 10 & 19,69 & 43,21 & 4,00 & 172,84 \\
\hline Lajes & Escada 1O & 94,86 & 148,70 & 4,00 & 594,80 \\
\hline Juntas & - & - & 103,85 & 2,00 & 207,69 \\
\hline Gd & \multicolumn{4}{|c}{}
\end{tabular}

\subsection{P03}

A Passarela 3 passou por intervenção de revitalização pela prefeitura em Junho/2019. Foram observados danos de pequena extensão, como resquícios de desplacamento (Figura 16) e exposição de armaduras (Figura 17), sendo estes em sua maioria cobertos por camada de pintura acrílica. Trechos com falhas de concretagem brandas, como na Figura 18, assim como fissurações com aberturas pequenas também foram observadas.

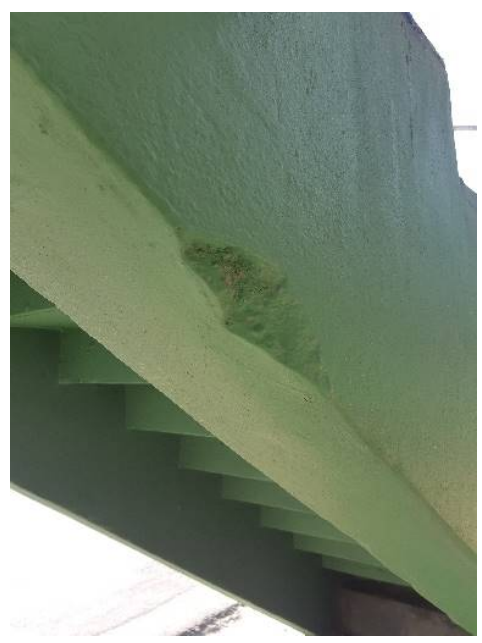

Figura 5: Desplacamento. $(\mathrm{Fi}=2)$.

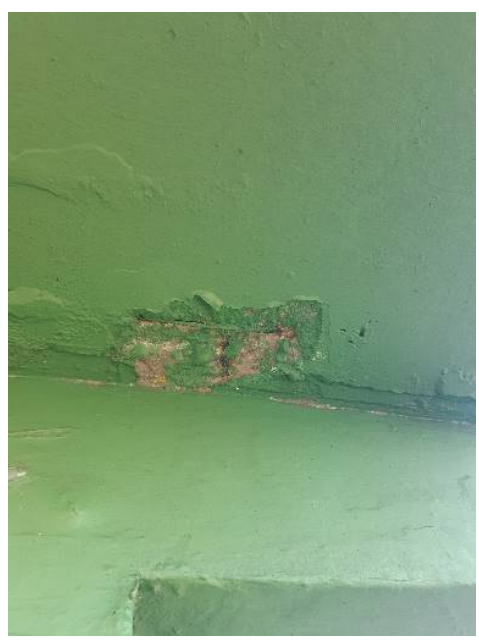

Figura 6: Exposição de armadura $(\mathrm{Fi}=2)$.

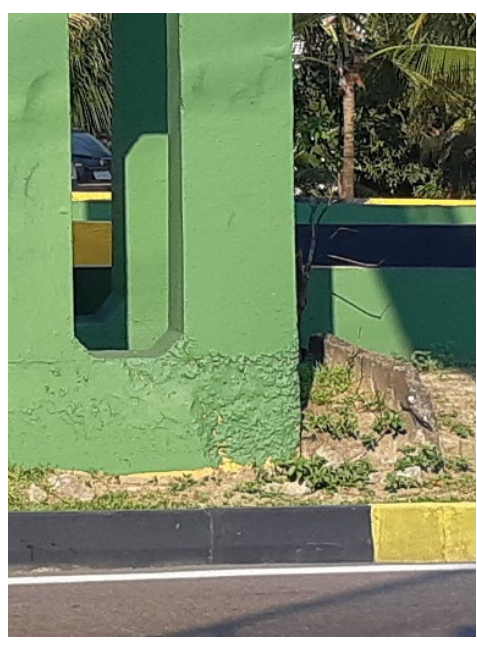

Figura 7: Falha de concretagem. $(\mathrm{Fi}=2)$.

Os resultados dos cálculos do grau de deterioração da P03 estão dispostos na Tabela 6. grau de deterioração da estrutura calculado foi de 15,17 , passando 17 centésimos da classificação de deterioração "Baixo", o que corresponde ao cenário desta OAE, recentemente revitalizada, com pequenos passivos para correção em manutenções futuras.

Tabela 6: Grau de deterioração da estrutura. P03.

\begin{tabular}{|c|c|c|c|c|c|}
\hline Família & $\begin{array}{l}\text { Elemento com } \\
\text { maior dano }\end{array}$ & Gde & Gdf & Fr & $\mathbf{K i}$ \\
\hline Pilares & Pilar 6 & 7,4 & 13,41 & 5 & 67,04 \\
\hline Vigas & Viga 5 & 8 & 14,64 & 4 & 43,93 \\
\hline Lajes & Lance 11 & 8,1 & 14,64 & 4 & 40,47 \\
\hline Juntas & - & - & 8,00 & 2 & 16,00 \\
\hline \multicolumn{5}{|l|}{ Gd } & 15,17 \\
\hline
\end{tabular}




\subsection{P04}

A passarela, inaugurada em Novembro de 2003, não apresentou indüivios de manutenções recentes. A P04 é representada nas Figuras 19 e 20.

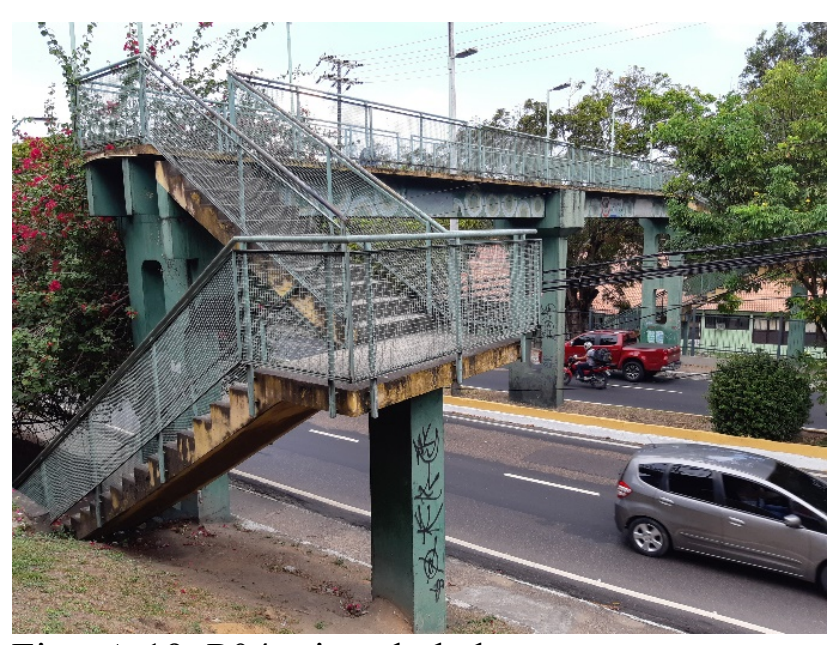

FigurA 19: P04, vista do lado norte.

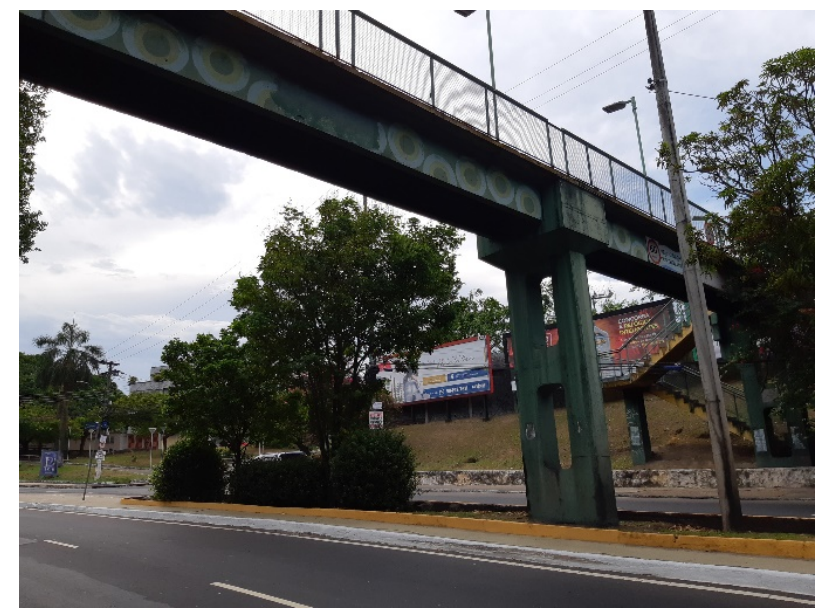

Figura 20: P04, vista a partir do lado sul.

O aspecto observado da estrutura denota grande ação da umidade na superfície, tendo as manchas como o dano mais recorrente de todos os elementos, ilustradas nas Figuras 21 e 22 Falhas de concretagem superficiais, como desprendimento de agregados, porosidade na superfície e desvios de geometria oriundos das formas também foram observados (Figura 23).

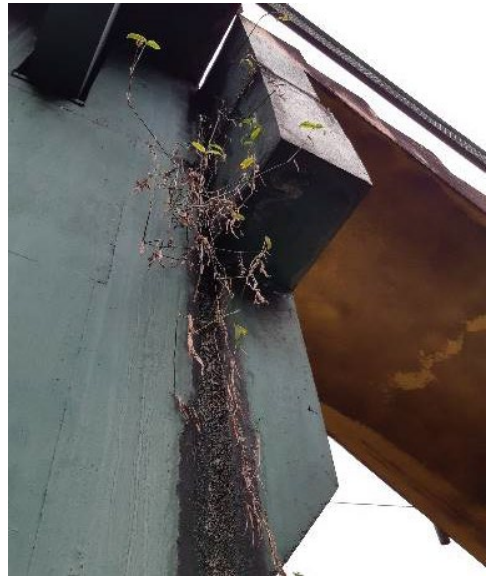

Figura 21: Manchas e surgimento de vegetação.

$$
(\mathrm{Fi}=3) \text {. }
$$

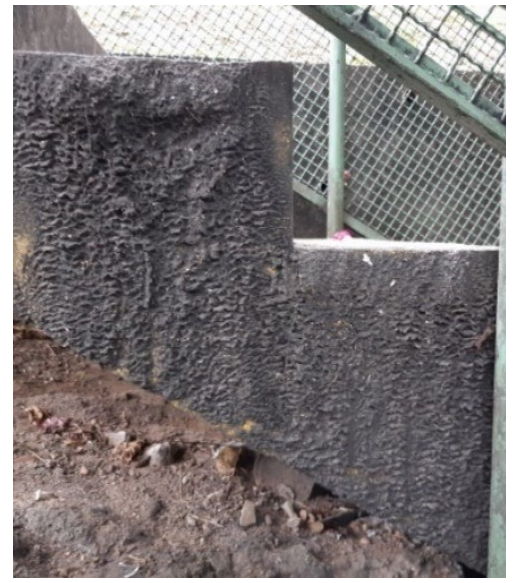

Figura 22: Manchas em estado avançado $(\mathrm{Fi}=3)$.

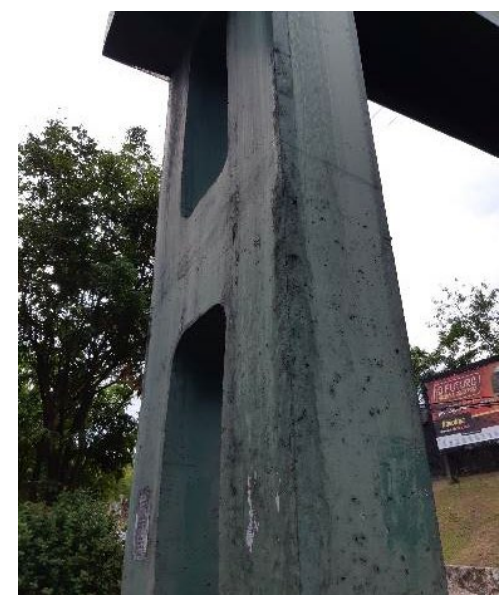

Figura 23: Falhas de concretagem $(\mathrm{Fi}=1) \mathrm{e}$ manchas em pilar $(\mathrm{Fi}=1)$.

Os danos de maior intensidade foram observados nas lajes do tabuleiro de travessia dos pedestres. Extensivos trechos apresentaram desgaste parcial ou total das juntas de dilatação (Figura 24), desplacamento da porção superficial (Figura 25) manchas de umidade (Figura 26): 


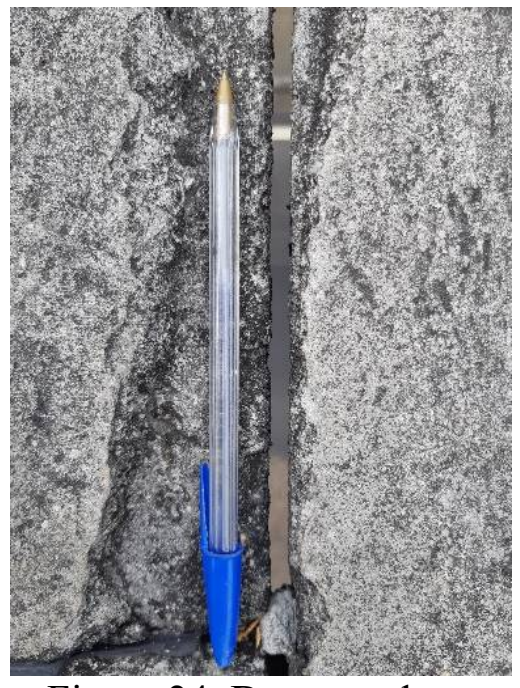

Figura 24: Desgaste do material da junta $(\mathrm{Fi}=4)$.

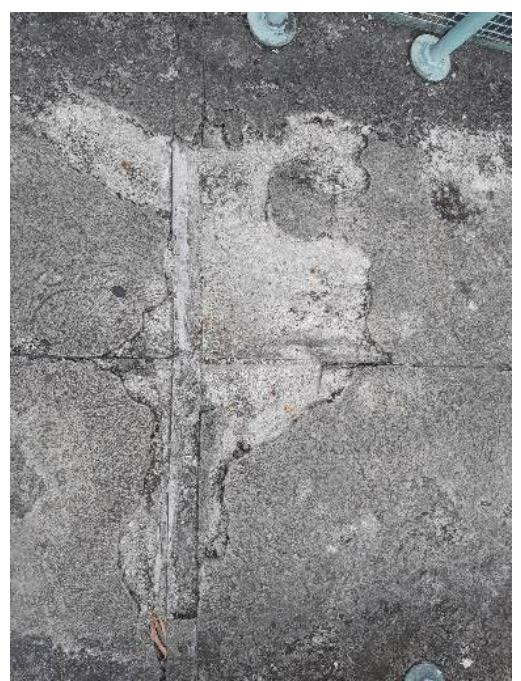

Figura 25: Desplacamento de do tabuleiro $(\mathrm{Fi}=3)$.

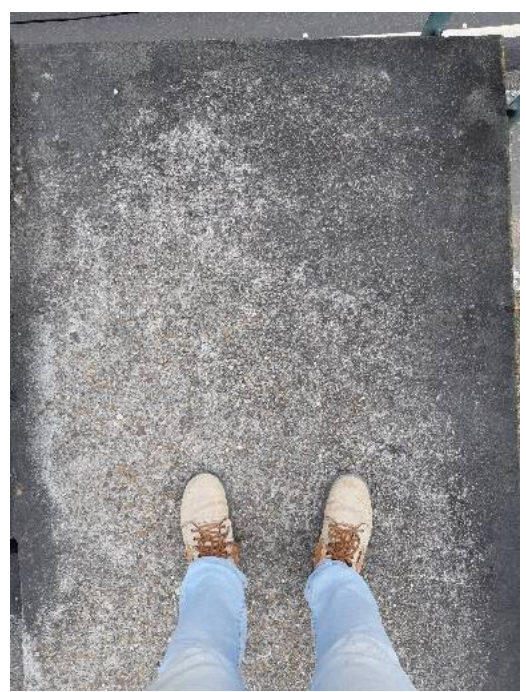

Figura 26: Manchas de umidade $(\mathrm{Fi}=2)$.

O grau de deterioração calculado foi 47,99, considerado Médio. A família de elementos com maior dano é a das lajes, seguida dos pilares. A tratativa para esta OAE requer planejamento de intervenção de até 2 anos. Ao que se refere às lajes, estas possuem grau de deterioração próximo de 51, considerado um nível "alto" pela metodologia. Recomenda-se a definição de uma inspeção especializada e o planejamento de ações intervencionistas em até 1 ano. Os resultados obtidos se encontram na Tabela 7.

Tabela 7: Grau de deterioração da estrutura. P04.

\begin{tabular}{|c|c|c|c|c|c|}
\hline Família & $\begin{array}{c}\text { Elemento com } \\
\text { maior dano }\end{array}$ & Gde & Gdf & Fr & $\mathbf{K i}$ \\
\hline Pilares & Pilar 3 & 3,90 & 39,16 & 5 & 195,80 \\
\hline Vigas & Viga 4 & 6,98 & 11,49 & 4 & 45,96 \\
\hline Lajes & Laje 5 & 33,00 & 50,27 & 4 & 201,10 \\
\hline Juntas & - & - & 100,00 & 2 & 200,00 \\
\hline \multicolumn{5}{|l|}{ Gd } & 47,99 \\
\hline
\end{tabular}

\subsection{P05}

A passarela 5, ilustrada na Figura 27, passou por processo parcial de revitalização, recebendo nova camada de pintura em boa parte de seus elementos, e recuperações em argamassa cimentícia em alguns trechos. Não há informações quanto à inauguração e identificação desta OAE. 


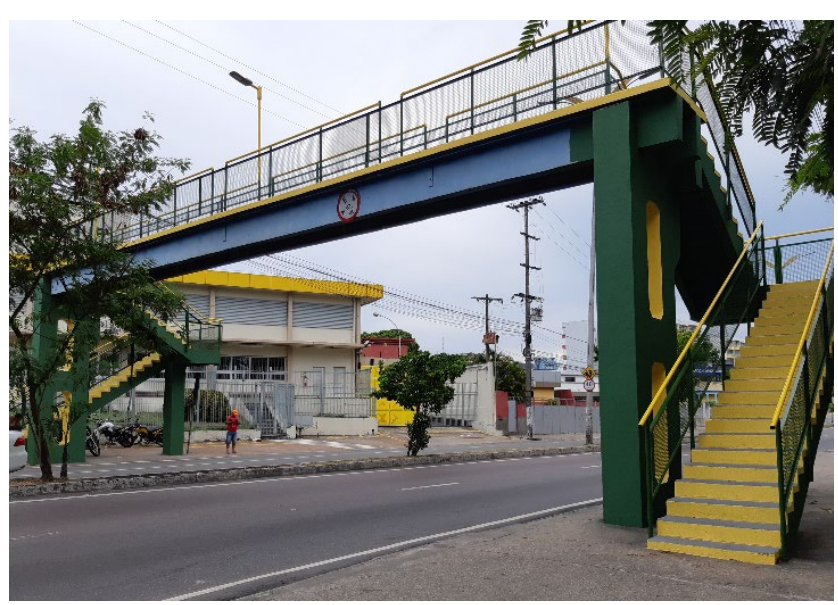

Figura 27: P05.

As Figuras 28 e 29 apontam a manifestação de manchas e eflorescências, observadas no fundo das lajes e faces internas das vigas. Há incidência de fissuração ao longo de ambas vigas, na face externa, normais ao eixo, sendo provavelmente oriundas de esforços de flexão nos elementos (Figura 30).

As vigas do lance superior da escada do lado sul apresentaram indícios de danos nas faces internas, sendo estes recobertos por pintura acrílica. Foi detectada fissuração apenas na parte inferior e paralela ao eixo. Foram evidenciados também pontos com desplacamento e exposição de armaduras.

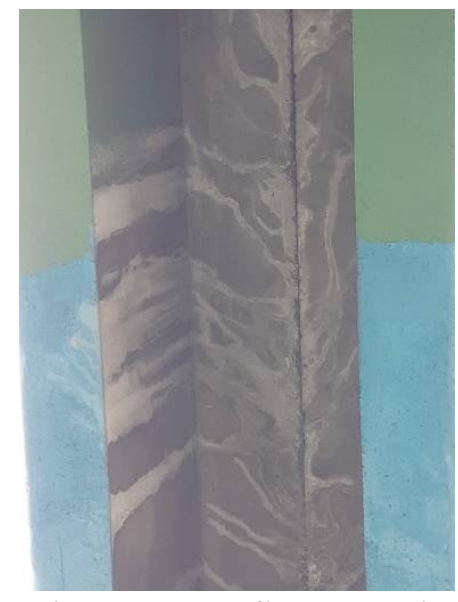

FigurA 28: Eflorescência $(\mathrm{Fi}=2)$ e manchas $(\mathrm{Fi}=1)$.

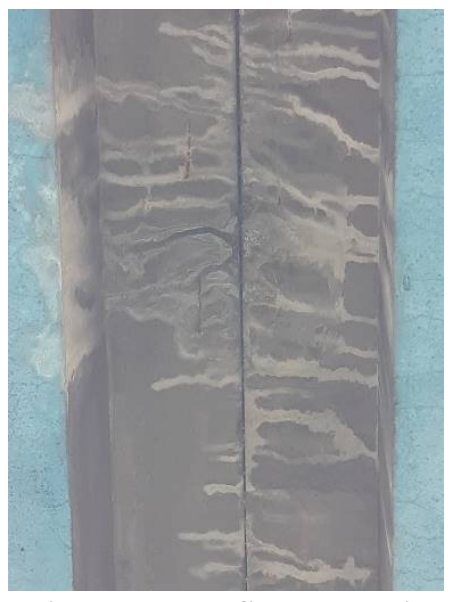

Figura 29: Eflorescência $(\mathrm{Fi}=2)$ e desplacamento. $(\mathrm{Fi}=1)$.

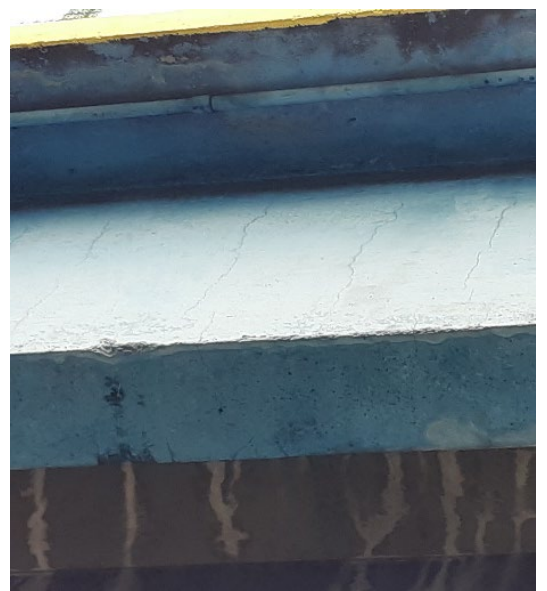

Figura 30: Fissuras de flexão $(\mathrm{Fi}=1)$ em vigas.

A Figura 31 ilustra a formação de uma fissura ao longo da viga 5. Outros danos foram identificados (Figuras 32 e 33) porém, de baixo grau de dano. A Tabela 8 dispõe os resultados. 


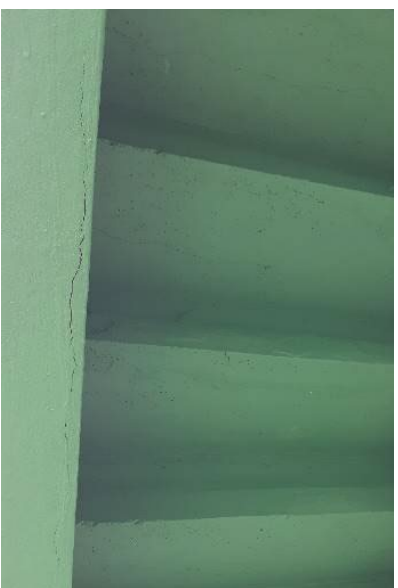

Figura 31: Fissuras $(\mathrm{Fi}=1)$.

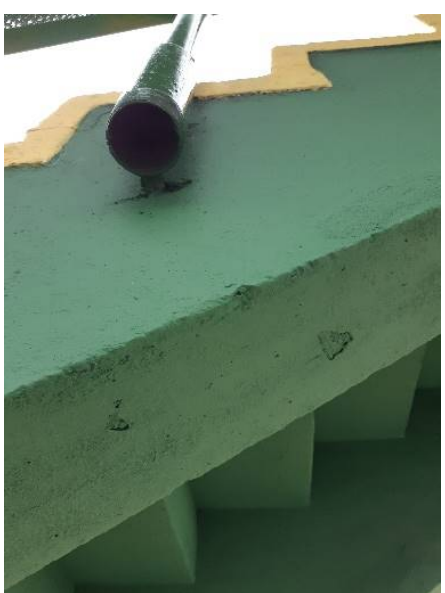

Figura 32: Falhas de concretagem $(\mathrm{Fi}=1)$.

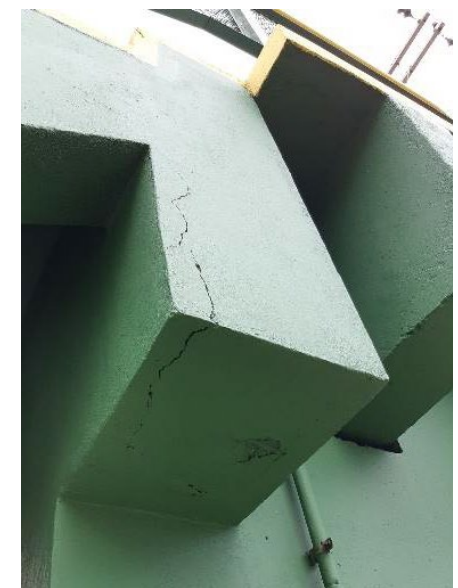

Figura 33: Fissuras $(\mathrm{Fi}=1)$. Armadura exposta $(\mathrm{Fi}=1)$

Tabela 8: Grau de deterioração da estrutura. P05.

\begin{tabular}{c|c|c|c|c|c}
\hline Família & $\begin{array}{c}\text { Elemento } \\
\text { com maior } \\
\text { dano }\end{array}$ & Gde & Gdf & Fr & Ki \\
\hline Pilares & Pilar 1 & 2,40 & 4,20 & 5 & 21,00 \\
\hline Vigas & Viga 6 & 11,56 & 20,94 & 4 & 83,75 \\
\hline Lajes & Laje 4 & 7,38 & 12,13 & 4 & 48,51 \\
\hline Juntas & - & - & 0,00 & 2 & 0,00 \\
\hline Gd & \multicolumn{3}{|l}{17,22} \\
\hline
\end{tabular}

\section{CONCLUSÕES}

A Tabela 9 apresenta o resumo dos resultados obtidos das inspeções realizadas nas 5 passarelas. Foram indicados também, o máximo grau de deterioração de família de elementos obtidos em cada OAE.

Tabela 9: Grau de deterioração calculados.

\begin{tabular}{c|c|c|c|c|c}
\hline $\begin{array}{c}\text { Grau de } \\
\text { deterioração }\end{array}$ & P01 & P02 & P03 & P04 & P05 \\
\hline Gd & 46,91 & 127,96 & 15,17 & 47,99 & 17,22 \\
\hline Gdf max & 53,12 & 148,70 & 14,64 & 50,27 & 20,94 \\
\hline
\end{tabular}

A partir da aplicação da metodologia GDE/UnB pôde-se quantificar a deterioração de cada estrutura das passarelas apontadas, como apresentado anteriormente na tabela 15. A P02 apresentou maior grau de deterioração $(\mathrm{Gd}=127,96)$, seguida das P04 $(\mathrm{Gd}=47,99), \mathrm{P} 01(\mathrm{Gd}=46,91), \mathrm{P} 05$ $(\mathrm{Gd}=17,22)$ e a $\mathrm{P} 03(\mathrm{Gd}=15,17)$.

A metodologia se revelou eficiente a relacionar com precisão as análises das inspeções visuais com o grau de deterioração de cada passarela, além de possibilitar a ordem de prioridade de ações preventivas a serem realizadas. O máximo grau de deterioração de uma família de elementos (Gdf) 
em cada passarela se aproxima do grau de deterioração da estrutura (Gd), como demonstrado na Tabela 10.

As passarelas possuíam sistemas construtivos similares, o que pode indicar período de execução próximo. A única referência de data é da P04, inaugurada em 2003. As idades destas OAEs se tornam importantes para indicar o desenvolvimento da vida útil das mesmas, possibilitando acompanhamento correto da estrutura ao longo do tempo.

Sinais evidentes da falta de manutenção resultaram na prevalência de manifestações patológicas em todos os elementos das passarelas, necessitando a criação de planos de ação de manutenção em caráter imediato pelo poder público.

Alguns danos observados necessitam investigação mais aprofundada, especialmente as fissuras e seções desplacadas. Por conta da exposição à impactos, e o desconhecimento do processo de corrosão que pode estar ocorrendo dentro da estrutura, a análise não pode concluir quanto às origens, estas sendo diversas.

A inspeção realizada, porém, encontrou dificuldades quanto ao acesso de alguns elementos, por se tratar de passarelas em travessia de vias de fluxo intenso de veículos. Os resultados, porém, apresentam precisão favorável.

\section{REFERÊNCIAS}

ASSOCIAÇÃO BRASILEIRA DE NORMAS TÉCNICAS. (2014). NBR 6118: Projeto de estruturas de concreto - Procedimento. Rio de Janeiro.

ASSOCIAÇÃO BRASILEIRA DE NORMAS TÉCNICAS. (2016). NBR 9452: Inspeção de pontes, viadutos e passarelas de concreto Procedimento. Rio de Janeiro.

CASTRO, E. K. (1994). "Desenvolvimento de metodologia para manutenção de estruturas de concreto armado". Masters Thesis, Universidade de Brasília.

EUQUERES, P. (2011). "Metodologia de inspeção de pontes de concreto armado". Masters Thesis, Escola de Engenharia Civil, Universidade Federal de Goiás.

MEHTA, P. Kumar e MONTEIRO, Paulo J. M. (2014). "CONCRETO. Microestrutura, Propriedades e Materiais". 2 ed. São Paulo, IBRACON.

VERLY, R. C. (2015) "Avaliação de metodologias de inspeção como instrumento de priorização de intervenções em obras de arte especiais". Master Thesis - Universidade de Brasília..

VITÓRIO, J.A.P. (2006). "Vistorias, Conservação e Gestão de Pontes e Viadutos de Concreto". $48^{\circ}$ Congresso Brasileiro do Concreto, 2006, Rio de Janeiro. Anais: CBC2006, IBRACON. 